by circumstances. The lesions met with and the treatment to be adopted are the same as in cases of traumatic epilepsy. In many instances we shall find unsuspected depressions of the bone; sometimes these will be found to have involved the inner table only, having presented no external evidence of their existence. Splinters of bone may be discovered pressing inwards or actually penetrating the dura mater. We must never omit to explore the inner surface of the bone by passing a probe between it and the dura mater for some distance around the trephine opening. Thickening and adhesions of the cerebral membranes are best treated by excision of the part of the membranes involved; any measure short of this will fail. Intrameningeal cysts containing blood or serum may be found but can seldom be diagnosed before the dura mater is opened. The smaller cysts can often be removed entirely; with the larger ones this is impossible. In the latter case the cyst should be opened, its walls cut away as far as possible, and the remaining part treated by gentle scraping and the applica tion of a solution of 1 part in 10 of carbolic acid. Unless this is done a persistent sinus may follow. If in the course of the operation we have reached the cortex of the brain without tinding any definite lesion to account for the symptoms the cerebral cortex must be carefully scrutinised and palpated. Cortical cysts are occasionally met with; if superficial they are readily recognised, if deep we find some localised tumidity, impairment or absence of the cerebral pulsation, and a feeling of increased resistance on palpation. In doubtful cases a long narrow scalpel should be introduced directly into the region of the suspected cyst. The other lesion which may be found comprises scarring and sclerosis of the cortex. In such cases it has been proposed that the diseased area should be excised but I believe that more harm than good will usually be done. If as the result of the operation no lesion of any kind is found we have at least the satisfaction of knowing that cure of the symptoms may follow, althongh we can apparently point to no step in the operation which is responsible for this result.

I must briefly refer to one or two of the most general steps of the operation. First, the simple trephine is undoubtedly the best means which we possess at present for opening the skull. Numerous other mechanical and electrical devices have been invented to take the place of the trephine but these all fail in one essential point: the sense of touch is lost by their use. In addition they are complicated, difficult to keep aseptic, and very liable to get out of order.

Secondly, large trephines only should be used and all trephines with a diameter of less than one inch should be abolished for these operations. It is essential for success to start with a large opening. If a half-inch crown of bone be removed it is impossible as a rule to deal adequately with the diseased parts; whilst to start with a small opening and to enlarge it afterwards is a slow and unsurgical method. For general purposes a trephine with a diameter of one and a quarter inches is most serviceable. There is one other instrument which is indispensable in these operations and that is Hoffmann's bone-cutting forceps. They are the most useful means of rapidly enlarging the trephine opening in any require $\lambda$ direction.

The third point which I wish to bring forward here, is that if it is decided to deal with any extensive lesion of the brain itself the operation must be performed in two stages. The only argument which $I$ need adduce in favour of this proposition is that the mortality in these operations if completed in one stage is very high, patients being unable to withstand the serious shock resulting, whilst if the opera tion be performed in two stages comparatively little shock follows. At the primary operation, then, a large opening in the skull, $u$ ually about three inches in diameter, is made and the flap which has been raised is sutured into place again. A fortnight later the flap is turned down and the diseased area is dealt with.

Lastly, there is the question of adhesions between the brain and the overlying tissues after operation. When thickened and adherent meninges have been excised it is clear that extensive adbesions may form and a strongly contracting cicatrix may result. The objects of the operation will thus be defeated and symptoms will recur. It is useless to talk about the prevention of adhesions : they will form in spite of anything that may be done. Our aim must be to reduce them to a minimum. In order to effect this various substances, such as gutta-percha tissue, egg-membrane, and gold foil, have been placed between the cortex and the structures lying over it. Of these I believe that gold foil is the best at the present time. In the future we may discover some more natural tissue for the purpose. The gold foil is cut very slightly larger than the opening in the dura mater and is then carefally inserted between the brain and the cut edges of the dura mater, the greatest care being taken to leave it lying quite smoothly. The bone, of course, is not replaced.

To sum up briefly, the following are the conclusions to which I have come in regard to treatment. 1. In rather more than half of the cases cure may be brought about by medical measures; prolonged mental rest and the proper administration of mercury are the essential points. 2. In a few of the cases the symptoms are mainly due to chronic osteo-sclerosis and such cases may be almost certainly cured by trephining. 3. In the remainder of the cases the symptoms are more persistent and do not yield to general measures or to the removal of thickened bone only. I believe that in such cases these symptoms are the reflex results of lesions or irritations of the dura mater; and if the injury bas involved the vault of the skull cure can be effected promptly by excision of the thickened or adherent dura mater and removal of any other source of irritation which may be present.

\section{A CASE OF}

\section{RUPTURE OF A TUBAL PREGNANCY ON} THE NINETEENTH DAY AFTER CONCEPTION AND TEN DAYS AFTER THE UTERUS HAD BEEN CURETTED. ${ }^{1}$

BY WILLTAM DUNCAN, M.D., F.R O.S., OBSTETRIC PHYSICLAN TO THE MIDDLESEX HOSPITAL.

THE patient, aged 27 years, was married in 1900. She consulted me in October, 1901, for menorrhagia. The periods, which commenced at the age of 12 years, were quite regular, lasting four days, until the early part of 1901, when they began to increase in amount, with pain, the passuge of clots, and a muco-purulent intermenstrual discharge. The patient was a healthy looking but pale woman of very active temperament. On examination the uterus felt a little enlarged, was somewhat tender on palpation, in normal position, and freely mobile. Nothing abnormal could be felt in either the lateral or posterior fornices. Per speculum the os uteri was eroded and some purulent discharge was seen exuding from it. I diagnosed fungous $\epsilon$ ndometritis and recommended that the uterus should be curetted. The patient went into a nursing home and I dilated the uterus (under anæsthesia) np to No. 14 Hegar and scraped away a very hypertrophied endometrium; the uterus after having been swabbed out with liquor iodi was packed with iodoform gauze for 48 hours. At the end of that time the gauze was removed and a vagiral douche of a 1 in 4000 solution of perchloride of mercury was ordered to be given night and morning whilst the patient remained in the home (this is my usual method of treatment after curetting the uterus). The patient made a perfectly uneventful recovery and returned home well after three weeks. I saw nothing more of her until the beginning of last November (1903) when she again consulted me for a recurrence of the menorrhagia. She then informed me that she had had a miscarriage at the third month at Christmas, 1902, and that since that time the periods had been $\epsilon$ xcessive and with clots. Since the miscarriage she had never missed a period. On examination I found a similar condition of things to that present when she consulted me in 1901, except, perhaps, that the aterus was somewhat more bulky than on the former occasion, but nothing whatever abnormal was detected in either fornix. As the next period was due in a few days it was decided that the curettage (which $I$ again advised) should be deferred until a couple of days after the period had ceased. This occurred on Nov. 14th after a week's loss ; accordingly, on Nov. 16th I went to the patient's home and with the assistance of Mr. Arthur John Hogg of Ealing (under whose care the patient had placed herself and 1904. 
to whose skill and unremitting attention the favourable termination of this most interesting case is largely due) I again curetted the nterus, removing (as on the former occasion) a very hypertrophied endometrium, but one which did not in the least raise in my mind the suspicion of its being a decidual membrane. The patient progressed uninterruptedly well, having neither pain nor rise of temperature until Nov. 25th, when rupture took place. At 9 P.M. on that day Mr. Hogg rang me up on the telephone and asked me to go to see the patient as she was ill. He told me that he had paid his usual visit about 2 P.M., when she was quite well, laughing and joking and saying that she would get up next day. On returning home from his round of professional visits at 7 P.M. he found a letter from the nurse asking him to send something to relieve the patient as she complained of pain at the chest and indigestion. Almost directly after reading this letter he received an urgent message asking him to go at once to see the patient. This he did and on arrival he found her collapsed, pulseless, semi-conscious, and tossing about in bed with gasping respiration. $\mathrm{He}$ at once injected strychnine hypodermically and put hot bottles, \&c., to the extremities in order to remedy the collapsed condition. As the state of the patient continued serious he (as I have mentioned) summoned me. On my arrival soon after $10 \mathrm{P} . \mathrm{M}$. I found the patient practically moribund, pulseless, blanched, with the lips and gums very pale and the extremities cold. On palpating the abdomen $I$ found dulness in both flanks and over the hypogastrium; I thought also there was diminished resonance over the liver. It was evident there was internal rupture of something, with hæmorrhage, also that abdominal section, unless associated with or preceded by transfusion, would be certainly fatal, so not having the necessary apparatus and instruments I at once telephoned to my colleague, Mr. A. Pearce Gould, and fortunately found him at home and got him to come out immediately. Whilst waiting his arrival we prepared in readiness the operating table, also plenty of sterilised water. Mr. Gould arrived soon after midnight. The patient was at once placed on the table and was skilfully put under the influence of ether by Dr. R. P. Cockburn. Mr. Gould first started the infusion of saline fluid into the left submammary cellular tissue and handed the care of this over to Mr. Hogg, whilst he opened the left cephalic vein and performed intravenous transfusion (also of saline fluid). Immediately this trans. fusion was thoroughly started I opened rapidly the abdominal cavity which was found to be full of liquid blood, with some clots; the right uterine appendage was brought into view and it proved to be normal, but when the left appendage was drawn out it was seen that there was a small round perforation of the somewhat thickened tube near the aterine end (see Fig. 1). The broad ligament was quickly

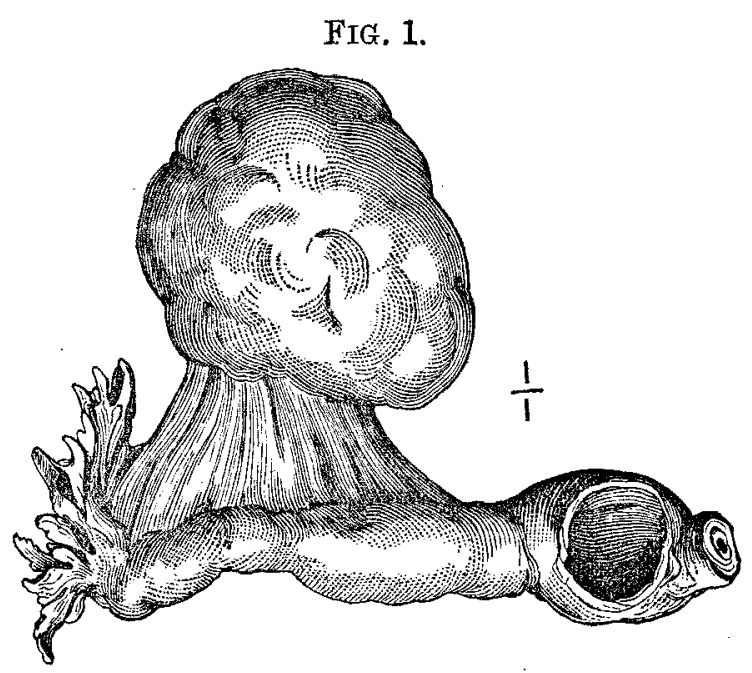

Left ovary and Fallopian tube showing ruptured gestation sac close to uterine end of the tube.

transfixed and tied in the usual way and the tube and the ovary were removed; most of the blood was sponged out from the abdominal cavity, which latter was also flushed with a lot of sterilised water, some of which was left inside; the abdominal wall was sewn up in three layers. Whilst this operation was proceeding nearly two quarts of saline fluid had been injected (submammary and intravenous). After the operation (which lasted from 20 to 30 minutes) the patient was returned to bed, still in an extremely dangerous condition, although the pulse was faintly perceptible at the wrist. Hot bottles were applied and injections of strychnine and an enema of brandy and beeftea were administered per rectum. When Mr. Gould and I left we could only give the relatives slight hope, everything of course depending on whether the patient could be kept alive for the next few hours. We left her in Mr. Hogg's care. At about 9 A.M. he telephoned the welcome news that the patient was alive, that her pulse was better and her temperature was normal, and that she was able to take nourishment. The subsequent history can be related in few words. The patient made an uneventful recovery and is now (Jan. 30th, 1904) quite well and getting about as usual.

This very interesting case presents several points for consideration.

1. The duration of pregnancy before rupture took place can be accurately stated to be the nineteenth day, as after recovery I went to see the patient in order to make sure of the date. She informed me that coitus took place on the Friday before her period commenced (namely, Nov, 6th) and not for some time previously. Before $q$ :estioning her I expected to hear that coitus had occurred on either of the two days which intervened between the cessation of the period and the curettage ; this would have given 11 or 12 days before rupture. However, the patient was very positive that no coitus tor $k$ place on either of those dates. So far as I can ascertain there is only one other case recorded in which rupture of a tubal gestation took place as early as the nineteenth day; that is one reported by $\mathrm{Mr}$. $\mathrm{E}$. Rumley Dawson. ${ }^{2}$ In that case the rupture, which was near the uterine end of the tube, is said to have occurred on the fifteenth day; the patient was a multipara and had not missed a period; internal hæmorrhage was diagnosed but no operation was performed and the ruptured tubal gestation was only discovered post mortem.

2. As regards diagnosis, when I first saw the patient there could be no question that she was suffering from fungous endometritis and although a tubal gestation was present when I curetted the uterus, seeing that it was only nine days old and that the history of the case was totally against pregnancy, I think it will be considered excusable my having failed to detect the slight enlargement of the left Fallopian tube which must have been present when I examined the patient under anæsthesia before proceeding to curette the uterus. The more I see of cases of extra uterine pregnancy (both in hospital and in private practice) the less value do I know can be placed on the history of a patient "having missed one or two periods." In many of these cases no such history can be obtained by the most careful questioning.

3. When Mr. Hogg rang me up on the telephone I confess I did not attach as much importance as I ought to have done to his statement that the patient (a few hours after he had seen her perfectly well) was collapsed and pulseless. I could not imagine anything having gone wrong in the pelvis ten days after curetting the uterus. However, on my arrival at the house, seting the patient blanched (she was naturally pale) and pulseless and finding dulness in the flanks and over the abdomen, it was at once obvious that rupture of something had taken place with extensive hæmorrhage which would ere long prove fatal unless operated upon. It seemed to me that the diagnosis lay between (a) rupture of a tubal gestation and $(b)$ perforation of a gastric ulcer with profuse bleeding. I leaned to the gastric ulcer view, as not only was the history completely against tubal pregnancy but also I could not imagine myself failing to detect an enlarged tube ; the fact also that on the afternoon of the accident the patient had complained of indigestion and pain at the epigastrium helped to obscure the diagnosis.

4. Whatever the cause of the condition was, it was perfectly certain that the abdomen must be opened, as no one suffering from rupture of any internal organ with severe hæmorrhage should be allowed to die without an exploratory operation having been performed. In this case the patient was too bad to be subjected to a severe operation without first (or at any rate simultaneously) transfusing her, and as I had not taken my transfusion apparatus with me it was indeed fortunate to be within telephonic reach of skilled help and all the necessary instruments. This case teaches the lesson always to carry a transfusion apparatus.

5. With regard to the parts removed it will be seen from

2 Transactions of the Obstetrical Society of London, 1893, vol. xl. p. 155 . 
Fig. 1 that the thickening of the Fallopian tube was comparatively slight, limited to the uterine half of the tube, and that the rupture took place near the uterus.

My friend Dr. W. F. Victor Bonney (obstetric registrar and tutor at the Middlesex Hospital) has made some excellent microscopical sections across the gestation sac and a beantiful drawing of one of these is here reproduced (Fig. 2). This

FIG. 2.

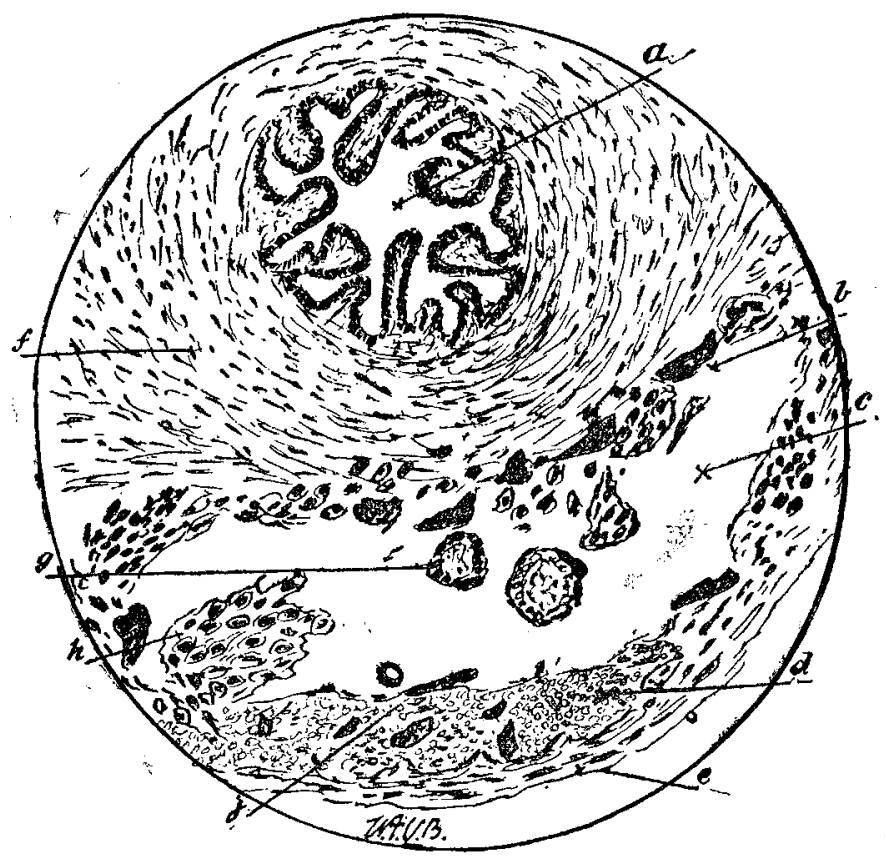

Transverse section of pregnant tube showing that the gestation sac is outside the lumen of the tube. $\times 75$. a, Fallopian tube; $b$ syncytial mass; $c$ gestation cavity; $d$ blood spaces in walls of cavity; , remains of tube ; $d$, blood peritoneum $f$ muscular wall of tube; $\theta$, villus wall and of large chorionic cells ; and $j$, syncytial mass.

very clearly shows the gestation sac to be altogether away from the lumen of the Fallopian tube and proves that what happens when a tubal gestation occurs is this, "the minute embryo burrows through the epithelial lining of the tube into the muscular coat where it develops.

\section{Pathological Report (on the parts removed) by Dr. VICTOB BONNEY.}

"The specimen consists of a Fallopian tube and attached ovary. The tube appears normal to the naked eye except at the junction of the isthmic and ampullary portions; here is situated a small hollow enlargement communicating with the outside by means of a clearly punched hole through which a small pencil might be passed. The cavity is principally in the tube wall, its outer wall being formed of thinly stretched tubal peritoneum, whilst its inner boundary is evidently in close connexion with the tubal lumen, though whether it communicates with it is impossible to determine without cutting cransversely across the tube at this point. On a transverse section being made across the tube on the uterine side of the punched-out aperture it is seen that the cavity is situated in the wall of the tube and does not communicate with the tubal lumen at any point Its outer wall is very thin, consisting practically of peritoneum only, but that towards the lumen of the tube is thicker and contains muscle elements. The course of the lumen of the tube is marked on the inner wall of the cavity as a curved elevated ridge much in the same way as the course of the aqueductus Fallopii is indicated on the inner and posterior walls of the tympanic cavity when the middle ear is opened up for dissection. The cavity contained clot and portions of chorionic villi.

"Mioroscopically the following appearances are seen. A considerable section of the tube and its contained gestation sac were removed and the continuity of the specimen restored by sutures. This section was then prepared and cut in serial sections to the number of about 150. The appearances of individual sections were practically the same. The tubal lumen appears intact and is separated from the gestation sac by a well-marked muscular layer (capsularis) of considerable thickness (see drawing of microscopical section, Fig. 2). The plicæ appear perfect, as is also the case with the columnar epithelium covering them. The tube is empty. The gestation sac is situated in the outer part of the tube wall. It contains well-marked chorionic villi with a distinct epithelium consisting of the two layers known as Langhans' and syncytial respectively. In many parts, however, a much greater thickness of the syncytial layer is observable and in those parts of the section where the villus was applied to the wall of the gestation sac these proliferating syncytial masses could be seen infiltrating the sac wall. The sac wall contains many spaces with blood, part of which appears to be surrounded by cells of embryonic origin. Many large cells, resembling decidual cells, are seen in the sac wall but these are continuous with masses of syncytium and in all probability are of embryonic and not of maternal origin. There, therefore, is an absence of any structure which could be described as 'decidual' and it is probable that such cells are strictly the derivative of the stroma cells of the endometrium and, therefore, do not occur when the ovum is situated in the midst of muscular tissue as (in the absence of a subepithelial stroma) it appears to be in tubal gestation. To this absence of decidual cells is probably to be ascribed the rapidity with which a tubal gestation erodes the walls of the gestation sac and brings about early rupture. The specimen is of great interest, bearing ont as it does the views put forward by all the modern German authorities and lately epitomised in Fngland by Dr. H. Russell Andrews that in all cases the implantation of the tubal gestation is in the muscular wall of the tube and not (as was formerly supposed) on the surface of the tubal epithelium and therefore within the tubal lumen."

Harley-street, W.

\section{SOME CLINICAL ASPECTS OF THE RHEU. MATIC INFECTION.}

BY CAREY COOMBS, M.D. LOND.,

MEDICAI REGISTRAR TO ST. MARY'S HOSPITAL, LONDON.

MANY writers-of whom W. B. Cheadle, ${ }^{1}$ T. Barlow, ${ }^{2}$ Angel Money, and J. F. Poynton and A. Paine ${ }^{3}$ may be mentioned-have spoken of the striking histological similarity shown by several of the rheumatic lesions, notably, the subcutaneous nodule and the various forms of cardiac inflammation, valvular, muscular, and peri. cardial, the features common and essential to each being more or less tissue necrosis surrounded by a zone of cellular proliferation which subsequently gives rise to fibrosis, the whole fading into normal tissue by way of gradually diminishing hyperæmia. Translating this piece of morbid anatomy into terms of morbid physiology, one may say that microscopical evidence goes to prove a similar reaction on the part of the body to rheumatic infection, whatever the organ or tissue affected.

The question naturally arising in one's mind is, Can one find clinical features of this reaction to rheumatic infection which, broadly speaking, appear whatever structure is affected? If the commoner forms of rheumatism-namely, articular, cardiac, and cerebral-be examined it is possible to find a certain clinical analogy which will now be briefly stated and illustrated by cases. In each of these forms of rheumatism can be found two extremes. At the bottom of the scale are the apparently transitory cases, in which the body seems to defeat its invaders easily : at the top of the scale are malignant cases-those in which the resistance offered to infection is of the feeblest. Between these extremes one finds absolutely every degree of disease : a more or less evenly balanced fight is waged between tissue and organism, leaving its mark on the former in the nature of connective-tissue overgrowth. This in turn produces more or less crippling of the tissues and interference with their functions. These cases of protracted infection fade at one end of the scale into those of the mild degree by way of cases with frequent relapse and recurrence; at the other end into the malignant varieties by way of chronic cases ending in a malignant outburst. The same idea is expressed by Garrod, ${ }^{4}$ who classifies rheumatic manifestations into 